\title{
INTRAMEDULLARY INTERLOCKING NAILING; WITHOUT IMAGE INTENSIFIER, ORTHO-TABLE AND X-RAYS - A RECOGNIZED TECHNIQUE. (A COMPARATIVE STUDY)
}

\author{
1. FCPS, FRCS \\ Consultant Orthopedic Surgeon \\ $\mathrm{CMH}$ Noshera \\ 2. FCPS \\ 3. Medical Student \\ Correspondence Address: \\ Dr. Fayyaz Ahmad Orfi, \\ Consultant Orthopedic Surgeon \\ $\mathrm{CMH}$ Nowshera \\ fayyaz_ao@hotmail.com \\ Article received on: \\ 20/09/2016 \\ Accepted for publication: \\ $15 / 12 / 2016$ \\ Received after proof reading: \\ $14 / 02 / 2017$
}

\section{Dr. Fayyaz Ahmad Orfi', Dr. Asrar Ahmad², Miss Maheen Orfi ${ }^{3}$}

\begin{abstract}
Static I /M I/L Nailing is considered to be the gold standard for fixing mid-shaft fractures of long bones. Flexible nails or plates are used in children for internal fixation of such fractures to avoid damage to epiphysis. Nailing is done under image intensifier using orthotable. These prerequisites are not available in all peripheral hospitals especially in a resource constrained country like Pakistan. A technique was evolved to do static I/M I/L Nailing without image and ortho-table while working under such conditions at $\mathrm{MASH}$ at $\mathrm{CMH}$ Muzaffarabad. The results were compared with the procedure done under image by the same surgeon. Study Design: Retrospective comparative study. Settings: Field Hospital (MASH) at $\mathrm{CMH}$ Muzaffarabad, CMH Kharian, CMH Malir and CMH Nowshera. Period of Study: Sep 2007 to March 2016. Material and Method: 165 cases of fracture femur, tibia and humerus were fixed with static I/M I/L Nailing without image intensifier while 148 cases of fractures of these bones fixed under image using ortho -table by the same surgeon were included in the study. Results: A minimum follow-up of 06 months was done and observations made regarding estimated blood loss, average time of operation (including anesthesia), and fracture healing time, weight bearing, early and late complications. Results are compared in two groups. Conclusion: I/M I/L Nailing for long bones fractures can be done without image intensifier ${ }^{11}$ or any intra-operative X-rays. ${ }^{4}$ Ortho-table is also not essential. Technique is simple. Opening the fracture site is not required in most of the cases. Minimal access is used when fracture site opening is required. It does not compromise any principle for internal fixation. Distal interlocking screws are applied without making a cortical window and their position is doubly confirmed intra-operatively by a simple technique (not mentioned in literature before this study). There are no added risks involved ${ }^{12}$ and results are comparable to the procedure done using image intensifier and orthotable.
\end{abstract}

Key words: $\quad$ Intra-medullary (I/M), Inter-locking (I/L), Combined Military Hospital (CMH)

Article Citation: Orfi FA, Ahmed A, Orfi M. Intramedullary interlocking nailing; without image intensifier, ortho-table and x-rays - a recognized technique. (A Comparative Study). Professional Med J 2017;24(2):282-287. DOI: 10.17957/TPMJ/17.3639

\section{INTRODUCTION}

Fractures shaft of long bones like femur, tibia and humerus are common. Their frequency has increased during the last two decades because of high velocity trauma. Implants used to achieve internal skeletal stabilization vary from DCP, LCP, Rush Nail, kuntcher's Nail, Flexible Ender's Nails and static Intra-medullary Interlocking Nails. External Fixators are used for open fractures or when there is associated Acute Compartment Syndrome. In adults for closed fracture shaft of tibia and femur static intra-medullary interlocking nailing has become a Gold Standard procedure. Most of the fractures mid-shaft of humerus can also be fixed with I/M I/L Nailing. However this procedure requires image intensifier, ortho table, lead aprons and radiation monitoring badges. All these parameters are not met easily in resource constrained $3^{\text {rd }}$ world countries especially in peripheral hospitals. Thus deserving patients are denied of the ideal fixation. They are resorted to alternative methods of plate fixation or conservative treatment which does not produce good results. An alternative and simple technique was developed while working in a peripheral hospital (MASH) in Muzaffarabad during post Oct 2005 earthquake era. It does not require image intensifier or any other radiological localizing method and can be done with or without ortho table. Per operative $X$ rays were not required ${ }^{12}$ 
and no basic principle of internal fixation was compromised. The technique is not only simple but also avoided risks of exposure to radiations. The results were compared with the same procedure done using image intensifier and ortho table by the same surgeon at other stations.

\section{MATERIAL AND METHOD}

This retrospective study was done at a field hospital (MASH) mainly 138 cases, and then continued at $\mathrm{CMH}$ Kharian, Malir and Nowshera. A total number of 172 cases of fracture femur, tibia and humerus were done in adults by without image intensifier and ortho-table. (Though in few cases done at Kharian, Malir and Nowshera without image ortho-table was available.) The results were compared with I/M I/L Nailing done by the same surgeon using image intensifier and ortho-table at various stations (151 cases). A minimum follow up of six months was done in all cases. 07 cases were lost in first group while 03 cases were lost in second group during follow up. Hence they were excluded from the study. Only adults with mid shaft fractures of long bone either closed or Gustillo 1 were included in the study. ${ }^{1}$ Informed consent was obtained in all cases especially when the procedure was performed without image intensifier.

\section{Technique}

Pre-operative X-rays were done of the fractured bone includng proximal and distal joints. Length of the Nail was estimated by measuring the normal (unbroken bone) of the patient and length of the guide wire per-operatively. Diameter of the nail required was calculated by largest flexible reamer used minus $2 \mathrm{~mm}$.

\section{Position}

In fracture humerus supine position with side arm extension was used. When traction table was not available lateral position was used for fracture femur $^{7}$ and supine position for fracture tibia.

\section{Incision}

For femur a $7 \mathrm{~cm}$ oblique incision was made above the greater trochanter for entry point. A $5 \mathrm{~cm}$ infra patellar midline incision splitting ligamentum patellae was made for tibia. While for humerus a $4 \mathrm{~cm}$ deltoid splitting incision above greater tuberosity was used to make the entry point.

\section{Reduction}

Using a minimal access to fracture site reduction was achieved in most of the cases of fracture femur so that peri-osteal blood supply was not jeopardized. However in 4 cases of exchange nailing guide wire was passed without opening the fracture site. While in cases of fracture tibia and humerus in about $60 \%$ of cases close reduction was achieved and guide wire passed across fracture site without opening the fracture site.

\section{Reaming}

All bones were reamed over the guide wire with flexible reamers to the maximum and then a nail of $2 \mathrm{~mm}$ less diameter of appropriate length was passed over the guide wire. This over-reaming of $2 \mathrm{~mm}$ decreases bending/de-shaping of the nail thus distal locking holes are displaced minimally.

\section{Locating Distal Locking Holes}

This is the main step in doing $\mathrm{I} / \mathrm{M} \mathrm{I/L}$ nailing without image. Two matching nails are selected with exactly overlapping distal holes. (Equal in length but diameter may differ). The one with desired diameter is passed over the guide wire so that proximal end of the nail lies flushed with the entry point cortex. Now the matching nail is overlapped with the nail passed and placed over the skin. Distance of the distal holes is marked at skin through the overlapped nail. Stab incision is made over the distal most hole. Distal holes are in the same medio-lateral plane as are the proximal locking holes in most of the locking systems of nails. So before drilling we placed the sleeve of the proximal holes in place to estimate the mediolateral plane. Guide wire is withdrawn into the proximal $1 / 3$ of the nail and drilling is done in the first cortex only by keeping the drill bit parallel to proximal sleeve till it touches the $2^{\text {nd }}$ cortex. Drilling is stopped and guide wire is again pushed distally. If the drill bit is passing through the distal locking hole it will hit the bit and give a metallic 
sound. This hitting can also be felt through the drill. If guide wire does not hit the bit, guide wire is withdrawn and drill bit is also withdrawn a little and another attempt is made through the same hole after minor adjustment in directions. In this regard nail can also be pushed further or pulled out a little if length adjustment is required or it can be slightly rotated. By using these techniques we were able to locate the distal hole blindly in most of the cases without making a second drill hole or a cortical window. No per-operative $\mathrm{X}$-rays were done which are not only time consuming but also disturb the sterile draping. Although there was a learning curve we never had to make a cortical window. Once guide wire hits the drill bit, length of the guide wire is marked with an artery forceps for future reference and it is withdrawn. Distal cortex drilled and locking screw is applied. Its position is again confirmed by hitting with guide wire at the same length. In the similar way proximal of the distal locking screw is applied and confirmed. It lies about $2.5 \mathrm{~cm}$ proximal to the distal hole. By retracting the nail a little at this stage and feeling the compression at fracture site further confirms the locking of distal screws.

\section{Caution}

Please do not operate drill while trying to hit the bit with guide wire. It may result in locking of the two inside the nail). Then proximal locking screws are placed with the help of a jig in traditional way and wounds closed. Position is confirmed by post-op X-rays in the evening in ward.

\section{RESULTS}

Without image a total number of 172 bones were fixed in 170 patients. 5 patients were lost in follow up so only 165 cases were included in the study. While using image 151 bones were fixed in 151 patients. 03 were lost during follow up so only 148 cases were included in the study. In without image group 112/165 (68\%) were male and $53 / 165(32 \%)$ were female. While in image group $97 / 148$ (65\%) were male and 51/148 (35\%) were female. Average Operating plus position setting timings in without image group were Femur 42 min, Tibia 22 min and Humerus 30 min while they were $58 \mathrm{~min}, 45 \mathrm{~min}$ and $35 \mathrm{~min}$ respectively in the image group. ${ }^{16}$ Decreased timings were mainly because patient's position setting time was markedly reduced. Estimated Blood Loss in without image group was Femur $200 \mathrm{ml}$, Tibia 80 $\mathrm{ml}$ and Humerus $100 \mathrm{ml}$ while it was $150 \mathrm{ml}, 70$ $\mathrm{ml}$ and $60 \mathrm{ml}$ respectively in with image group. Average Healing Time for fracture was Femur 112 days, Tibia 84 days and Humerus 67 days while in image group it was 102, 82 and 65 days respectively. Full weight bearing with little support in without image group was possible in femur after 60 days and in tibia after 38 days while in image group it was achieved in 58 days and 37 days respectively. Post op infection occurred in 4/ 165 cases (2.4\%) in without image group and $2 / 148(1.4 \%)$ in image group. All infections were superficial and treated with extended course of antibiotics according to culture and sensitivity report. In no case implant had to be removed because of infection. Implant failure occur in $5 / 165(3 \%)$ in without image group and in 4/ 148 $(2.7 \%)$ in image group. All of them were in lower limbs $^{2}$ were breaking of the nail in tibia (one in each group). They require change of implant (Exchange nailing). 07 cases were those of broken distal screws before dynamization. In all these cases cause for implant failure was early enthusiastic weight bearing. There were 02 cases of mild valgus deformity at fracture site in tibia in without image group and one case of varus deformity of femur in image group. These were because the fracture was in lower $1 / 4$ of the shaft and communitted. Therefore their correlation with the method used is not established. There was no case with significant $(>1 \mathrm{~cm})$ LLD in both the groups.

\section{DISCUSSION}

High velocity trauma is one of the common causes of morbidity and mortality in modern world. About 50 million people lose their lives annually in trauma. Those who survive have long bone fractures as the commonest injuries. Most of the people are between 20-50 years which is the most productive period of life. Making these people fit and bring them back to functionally normal in minimum time is the main goal of treatment. 


\begin{tabular}{|l|c|c|c|c|c|c|}
\hline & With Image & & & Without Image \\
\hline & Femur & Tibia & Humerus & Femur & Tibia & Humerus \\
\hline Operationg/ Anaesthesia Time & $58 \mathrm{~m}$ & $45 \mathrm{~min}$ & $35 \mathrm{~min}$ & $42 \mathrm{~min}$ & $22 \mathrm{~min}$ & $30 \mathrm{~min}$ \\
\hline Estimated Blood Loss & $150 \mathrm{ml}$ & $70 \mathrm{ml}$ & $60 \mathrm{ml}$ & $200 \mathrm{ml}$ & $60 \mathrm{ml}$ & $100 \mathrm{ml}$ \\
\hline Healing Time & 102 days & 82 days & 65 days & 112 days & 84 days & 67 days \\
\hline Weight Bearing & 58 days & 37 days & - & 60 days & 38 days & - \\
\hline Post-op Infection & & $1.4 \%$ & & & $3 \%$ \\
\hline Implant Failure & \multicolumn{3}{|c|}{ Table-I } & & \\
\hline
\end{tabular}
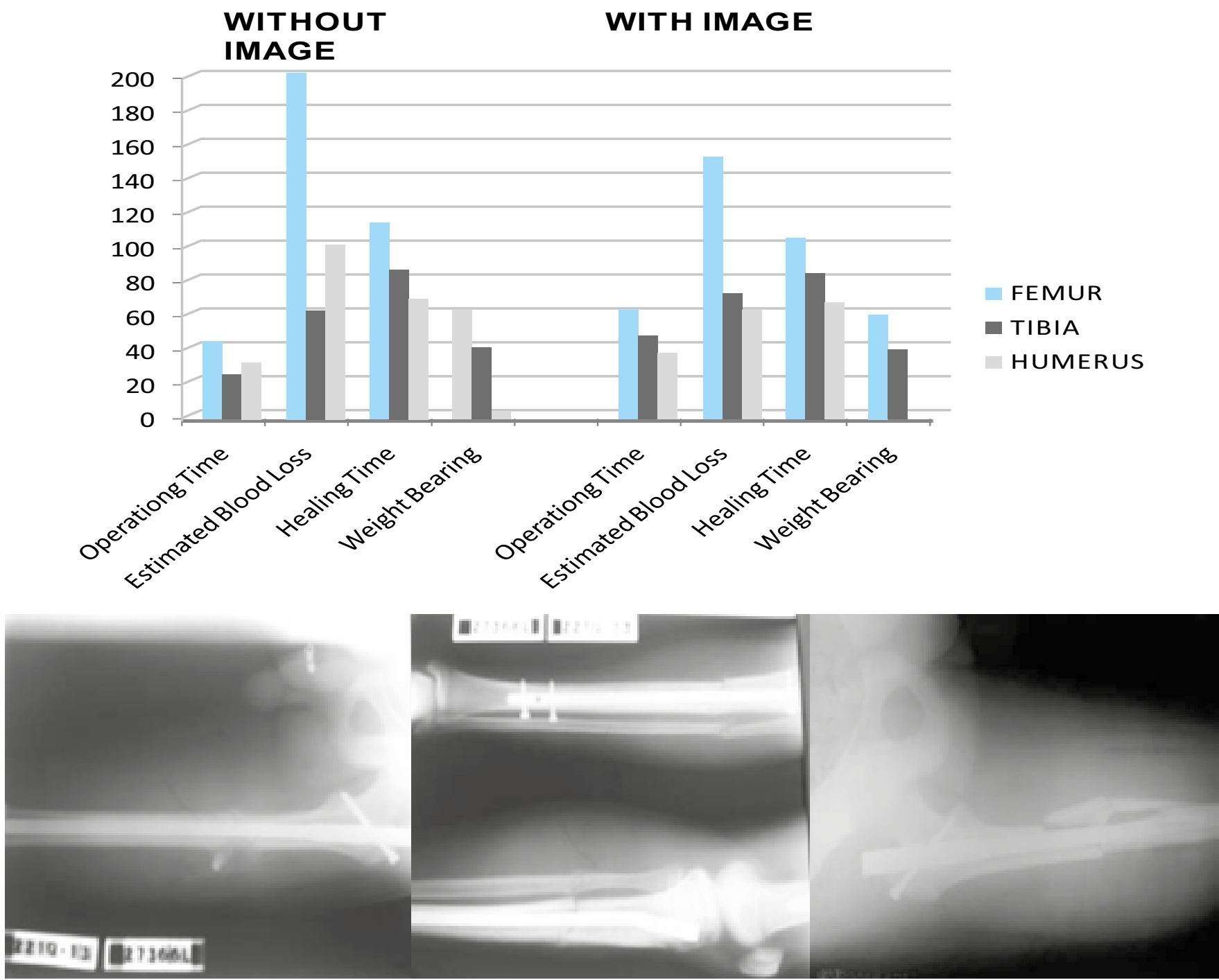

Fixing mid-shaft long bone fractures with I/M I/L nails is the gold standard to achieve that goal. ${ }^{2}$ This requires image intensifier and ortho-table during surgery. Moreover protective lead aprons and radiation exposure badges are required. These requirements are expensive and not always available in peripheral hospitals in a resource constrained countries like ours. This leads the orthopedic surgeons to treat those fractures with some sort of plates or conservatively. Both these have got inferior results as compared to $\mathrm{I} / \mathrm{M} \mathrm{I/L}$ nailing which is the gold standard for fracture tibia and femur. Referring all such cases to a tertiary care centers put extra burden on the 
family involved and not logistically possible some times. Providing appropriate treatment modality by orthopedic surgeons even under such circumstances is indeed highly desirable. This was the main theme behind this study. However it was important not to compromise on surgical principles and patient should not be exposed to any additional complications. Main advantages of $\mathrm{l} / \mathrm{M} \mathrm{I/L}$ nailing are early weight bearing and closed technique. We were able to follow this in most of the cases of fracture tibia and humerus. But in facture femur we have to resort to a minimum access approach to fracture site for reduction and passing the guide wire. The results of this study show that this minimal access does not interfere with the periosteal blood supply significant enough to prolong the healing time of the fracture. Thick muscular cuff around femur which hinders close reduction of the fracture acts as a protective factor against delayed/non-union even with open technique of minimal access. The technique used is simple and effective. No localizing radiation imaging is required. This minimizes the radiation exposure risks of OT staff to zero. No lateral cortical window is made to identify the distal interlocking holes as is done in other similar studies. This is not only time consuming but also make distal interlocking to uni-cortical hold which may compromise the stability of reduction especially in communitted fractures. Confirming the drill bit and locking screw inside the holes by hitting with the guide wire is a simple and surest technique to confirm the position of distal locking screws intra-operatively when image intensifier is not available. An identical length nail is used as a guide to locate the distal locking holes. No special jig was required. Using this simple technique all deserving patients can be managed with I/M I/L nailing even if image intensifier is not available.

\section{CONCLUSION}

Intramedullary interlocking nailing is the standard treatment for mid-shaft fractures of long bones especially in lower limb. It requires image intensifier and ortho-table. However these are not always available in peripheral hospitals in countries like Pakistan. But this procedure can be performed without these gadgets and not compromising the surgical principles at the same time. The technique is simple and useful but needs a learning curve and should only be attempted by orthopedic surgeons who have sufficient experience of doing that procedure under image intensifier and know the subject of $\mathrm{I} / \mathrm{M} \mathrm{I} / \mathrm{L}$ nailing well. This technique actually decreases the anesthesia time as position setting time for image is saved. Exposure to radiation of OT staff is reduced to zero. ${ }^{12}$ Even intra operative $X$-rays are not required. Though in most of the cases of fracture femur open reduction is to be done with minimal access but fracture healing and weight bearing time remain unchanged. ${ }^{16}$ Complications were few and within acceptable limits in this study. ${ }^{14}$ Above all quality of treatment is not to be compromised even in the absence of gadgets which were considered to be essential for the procedure. Thus standard orthopedic management can be done in deserving patients at a center which is not well equipped.

\section{Appreciations}

I appreciate the efforts of all my house officers and MO's who helped me in collecting the data for this study. Without their invaluable input this project would not have been a reality.

Copyright (C) 15 Dec, 2016.

\section{REFERENCES}

1. Brug E, Penning D. Indications for interlocking nailing. Unfall chirurg. 1990;93:492-498.

2. Garcia Juarez JD,Aguilera JM, Brenvenu AT, Encalada MT, Sheldon OD. Use of orthofix intermedullary nail in tibial shaft fractures- A review of 22 cases. Acta Orthop Mex 2007;21:212-216.

3. Giri SK. Achieving distal locking without an image intensifier. Nepal Med Coll J. 2007;9:275-277.

4. Giri SK, Adhikari BP, Bajracharya AK, Khatri K. Miniopen reduction and intramedullary interlocking nailing of fracture shaft of tibia without an image intensifier. Nepal Med Coll J. jun 2008;10(2):123-125.

5. Hashemi Najad A, Goddard NJ. A Simple jig to ease the insertion of distal screws in intra-medullary locking nails. Injury 1997:25(6);407-408.

6. Johnson D, Orgunlusi R, George B, Rose S. Interlocking nails without image-the challenge of locating distal slots and how to overcome them in SIGN I/M Nailing. 
Int Orthopedics. Oct 2009:22(1);201-204.

7. Krettek C, Konemann B, Farouk O, Miclau T, Kromm A, Ts cheme $\mathrm{H}$. Experimental study of distal interlocking of solid tibial nail:radiation independent distal aiming device(DAD) versus free hand technique (FHT). J Orthop Trauma. 1998;12:373-378.

8. Lin HT, Wang IC, Yu EM et al, Closed intramedullary nailing in lateral decuibitus position without a fracture table: a preliminary report of 15 patients. Chang Gung Med J.2005:28(9);629-635.

9. Nc Ferran MA, Jhonson KS. Intra-medullary nailing of acute femoral shaft fracture without a fracture table: technique of using a femoral distraction. $J$ orthopedics and Trauma. 1992;6(3):271-278.

10. Ozsoy MH, Basarir K, Kayramoglu A, Erdemli B, Tuccait EK, Siaglu MF. Risk of superior gluteal nerve and gluteus medius muscle injury during femoral nail insertion. J Bones \& Joint surg Am. 2007;899(4):829834.

11. Penning D, Oppenheim W, Faccioli G, Rossi S. Intramedullary locked nailing of femur and tibia,
Insertion of distal locking screw without image intense fier. Injury. 1997;28(4):323-326.

12. Steriopoulos KS, Kontakis GM, Katons PG, Galana kis IA, Dretakis EK. Placement of distal locking screws of femoral intramedullary nail without radiation. 1996;Arch Orthop Trauma Surg; 115(1):43-44.

13. Tanna DD. Interlocking nailing without an image intensifier. J Bones \& Joint Surg Brit. 1994;76(4):670.

14. Tueker MC, Schwappach JR, Leighton RK, Coue K, Ricci WR. Results of femoral intramedullary nailing in patients who are obese verses those who are not obese: a prospective multicenteric comparison study. J Orthop \& Trauma. 2007;21(8):523-529.

15. Winquest RA, Hanses ST, Clawson DK. Closed intramedullary nailing of femur fractures-a report of 520 cases. J Bones \& Joint Surg Am. 1984;6(4):529539.

16. Wolinsky PR, NcCarty EC, Slyr Y, Johnson KD. Length of operative procedures ; reamed femoral intramedullary nailing performed with and without a fracture table. J Ortop \& Trauma. 1998;12(7):485-492.

\section{PREVIOUS RELATED STUDY}

Mansoor llyas, Mohammad Idress, Siafuddin Tareen. INTERLOCKED INTRAMEDULLARY NAILING OF LONG BONES. (Original) Prof Med Jour 15(4) 449-454 Oct, Nov, Dec, 2008.

\section{AUTHORSHIP AND CONTRIBUTION DECLARATION}

\begin{tabular}{|c|c|c|c|}
\hline Sr. \# & Author-s Full Name & Contribution to the paper & Author =s Signature \\
\hline 1 & Dr. Fayyaz Ahmad Orfi & $\begin{array}{l}\text { Concept, Operating } \\
\text { Surgeon, Study Design }\end{array}$ & \\
\hline $\begin{array}{l}2 \\
3\end{array}$ & $\begin{array}{l}\text { Dr. Asrar Ahmad } \\
\text { Miss Maheen Orfi }\end{array}$ & $\begin{array}{l}\text { Observation, Data collection } \\
\text { Editing, References }\end{array}$ & \\
\hline
\end{tabular}

